\title{
Measuring Community Disaster Resilience using Q-Methods: A Physical Resilience Perspective
}

\section{Abstract:}

\section{Purpose}

Decision makers, practitioners and community members have a need to assess the disaster resilience of their communities and to understand their own capacities in disaster situations. There is a lack of consensus among researchers as to what resilience means and how it can be measured. This paper proposes a novel technique to achieve consensus among stakeholders on the definitions, objectives and indicators for measuring a key dimension of community disaster resilience, namely Physical Infrastructure (PI).

\section{Method}

This study uses a 5-step approach utilizing Q-methods to contextualize a resilience index for Physical Infrastructure. Interviews, focus groups and Q-sorting workshops were conducted to develop a tool that ranked measures according to stakeholder preference. A total of 84 participants took part in the workshops across four countries (UK, Malaysia, Pakistan and Sri Lanka).

\section{Findings}

The initial set of 317 measures was reduced to 128 and divided into the three community capacities of Anticipatory, Absorptive and Restorative. The Physical Infrastructure Capacity Assessment Tool (PI-CAT) was then finalized to encompass 38 indicators that were also ranked in order of importance by the participants.

\section{Practical implications}

The PI-CAT can be useful for local governments and communities to measure their own resilience. The tool allows stakeholders to be confident that the metrics being used are ones that are relevant, important and will meet their requirements.

\section{Originality}

The Q-method approach helps stakeholders to develop and use a community capacity assessment tool that is appropriate for their context. The PI-CAT can be used to identify effective investments that will enhance community disaster resilience.

Key Words: resilience, q methods, community, disaster management, Physical Infrastructure 


\section{Introduction}

Recent trends have shown that disasters result in increasing losses of life and in material damage (both to the socio-economic and built environments) and affect more than 200 million people around the world annually as well as inflicting annual losses of almost US\$180 billion (Irwin et al., 2016, UNISDR, 2019). Due to the rising frequency and magnitude of natural disasters occurring worldwide (Irwin et al., 2016) there is an increasing need for local decision makers, practitioners and community members to better assess the disaster resilience of their communities from their own perspectives (Jones, 2019). A more inclusive and participatory process of resilience assessment is required to better understand a community's capacity to anticipate hazard impacts, absorb disaster impacts and to restore basic functions to prior levels, or even to build back better (UNISDR, 2019).

The international development community has increasingly embraced the concept of resilience as a core strategy for communities as stated in Target 1.5 of the United Nations' 2015 Sustainable Development Goals (SDGs): 'Build the resilience of the poor and those in vulnerable situations, and reduce their exposure and vulnerability to climate-related extreme events and other economic, social and environmental shocks and disasters by 2030' (UN/ESCAP, 2015). This has led to resilience becoming a core mechanism for intervention design by many international agencies working on disaster risk reduction, poverty and issues of sustainability (Serfilippi and Ramnath, 2018).

Understanding and measuring Community Disaster Resilience (CDR) at the local level is often characterized by limited technical knowledge and disagreement about the nature of resilience itself, particularly the goals required to achieve it (Reyers et al., 2015). There exists a diversity of perspectives among academics, practitioners and community members (CDR stakeholders) on the understanding of resilience and this translates to different perspectives on measuring their community's resilience (Saja et al., 2018). A stakeholder perspective of community resilience includes their preferences concerning risk management and preparedness, as well as their explicit interests, and the knowledge that lies beneath these preferences (Raadgever et al., 2008). Stakeholder groups in the process of understanding and measuring CDR discover that finding the "right solutions for the right problems" in terms of building community disaster resilience requires reaching an agreement on the goals of an assessment (Reyers et al., 2015). Once stakeholders define these goals, they are better placed to participate in planning and managing risk reduction in their communities (Clare et al., 2017).

Developing an overview of the different stakeholder perspectives can increase an awareness of other groups' perspectives, may facilitate discussion and even support critical reflection on the rationality behind stated positions' methods (Andersen et al., 2007, Hovmand, 2014). As CDR can mean different things to different stakeholders, there is a need to develop tools to help address the questions concerning resilience to what, and of whom (Cutter, 2016, Patel et al., 2017). This research will define resilience in terms of the key community capacities that can be measured using a generic adaptable CDR framework. A resilience assessment which is based on more subjective methods seeks to be more inclusive to the needs and perspectives of the community and will help in greater customisation and contextualisation of the assessment at the community level (Jones, 2019).

This paper proposes a novel participatory approach to achieve consensus among stakeholders on the definitions, objectives and indicators for measuring a key dimension of community disaster resilience, namely Physical infrastructure (PI). The current research is part of an Engineering and Physical Sciences Council (EPSRC) funded Global Challenges Research Fund project called MOBILISE that aimed at developing a digital platform for multi-agency collaboration for disaster risk reduction 
and response. The first step concerns creating a tool for the assessment of the resilience capacities of $C D R$ at local levels and a closer stakeholder engagement in the resilience measurement process.

\section{Community Disaster Resilience}

As the concept of CDR continues to evolve, research is now increasingly focused on developing methods and tools for its measurement and classification (Sharifi, 2016, Cutter, 2018). Despite this growing importance, no clear definition for community resilience has emerged (Rogers, 2011, Serfilippi and Ramnath, 2018). Systematic reviews by Ostadtaghizadeh et al. (2015) and Koliou et al. (2018) have suggested that one of the definitions for resilience that has found consensus among a wide range of stakeholders is the definition used by the United Nations International Strategy for Disaster Reduction (UNISDR) (Ostadtaghizadeh et al., 2015, Koliou et al., 2018). UNISDR defines resilience as "the ability of a system, community or society exposed to hazards to resist, absorb, accommodate to and recover from the effects of a hazard in a timely and efficient manner, including through the preservation and restoration of its essential basic structures and functions" (UNISDR, 2013). However, operationalising this definition presents its own set of challenges. These challenges can range from methodological issues (i.e. measuring "soft" variables like social and human relationships) to the role of power and influence in building resilience (i.e. equitable representation in resilience assessments), the lack of any direct measures of hazards being used in the assessment and the temporal dynamics of resilience over time.

Although the terms resist, absorb and recover are used in the UNISDR definition, it is important to realize that these are distinct processes that can vary from hazard to hazard, place to place and country to country (Constas et al., 2014). Therefore, one of the main challenges for resilience quantification is the operationalisation of these processes, particularly when capturing the hazard itself, and the cultural and national diversity that exists in the global context (Saja et al., 2018). In addition to developing a robust operational definition, it is important to identify the variables and processes that influence or predict resilience as well as the variability of resilience within different communities (Serfilippi and Ramnath, 2018).

Community resilience in the literature can be defined as a system's capacity to rebound or to return to a state of equilibrium following an external disturbance (Cimellaro et al., 2010, Peck and Simonovic, 2013). The way these capacities are defined and operationalised in the literature range from being the relatively simple direct measures of disaster impact to complex indices representing aspects of a community's capacity (Irwin et al., 2016). Hence, to better understand and measure these processes, a more subjective approach, where stakeholders play a more participatory role in defining resilience capacities and how to measure them, can help to operationalize CDR (Jones and Tanner, 2017). This research adopts the approach used in the literature that links community resilience to community capacities and has defined these as the three capacities (anticipatory, absorptive and restorative) that best represent the processes mentioned in the UNISDR definition (Thayaparan et al., 2016, Tariq et al., 2020).

In this study, Anticipatory capacity is defined as the ability of a system to anticipate and reduce the impact of climate variability and extremes through preparedness and planning (Bahadur et al., 2015). This is considered as a proactive action before a foreseen event to avoid disturbance, either by avoiding or reducing exposure or by minimising vulnerability to specific hazards (Kellett and Peters, 2014).

Accordingly, Absorptive capacity is considered as the ability of a system to buffer, bear and endure the impacts of climate extremes in the short term and avoid collapse (death, debilitation and destruction of livelihoods) (Wisner et al., 2004, Folke et al., 2010, Béné et al., 2012). This is, also, the 
ability of people, organizations and systems, using available skills and resources, to face and manage adverse conditions, emergencies or disasters (UNISDR, 2009).

In the case of Restorative capacity, the study defines it as the ability of a system to be repaired easily and efficiently (Biringer et al., 2013). In the context of critical infrastructure, system repair is the distinguishing feature of restorative capacity and it has been claimed as the final line of defence that requires the greatest amount of effort. This capacity is also linked to the terms adaptive and transformative where communities respond by learning and using their knowledge and experience to "build back better" over the long run (Constas et al., 2014).

This research has chosen the above three capacities as those which are most suited to characterise a community resilience assessment process (Thayaparan et al., 2016). The use of the three capacities outlined above has been undertaken to address some of the key limitations and challenges faced by researchers in developing measures of community resilience as specified in the literature (Levine, 2014, Beccari, 2016). Each of these capacities generated a set of objectives for measurement from the literature forming the basis of the activities in preliminary stage of the research as discussed in the next section. The initial set of objectives, and the final selected ones, are presented in Table 3.

By using community capacity assessments as the basis of measuring community resilience, researchers can address some of the challenges and make a more robust, valid and "fit-for-purpose" resilience measurement tool. Fit-for-purpose tools are designed by the users themselves to measure processes that they need to measure rather than through the perspective of external researchers. For example, by allowing a greater say by community members (and other key stakeholders) to define how these capacities are measured, more direct measures (those that may matter more to the relevant stakeholders for local resilience issues) can be included (Jones, 2019). To be used effectively for decision making, community capacity assessments must also correspond to the appropriate systems or dimensions of a community that best describe the resilience issues affecting it, e.g. the physical infrastructure and elements of the built environment or other aspects of the community.

\section{Dimensions of Community Disaster Resilience}

It was essential for the research team to initially select what dimensions of CDR would be included in the classification of measures/indicators so that a preliminary library of measures could be formed (Ostadtaghizadeh et al., 2015, Irwin et al., 2016, Links et al., 2017). A literature review was conducted resulting in the selection of six dimensions of community disaster resilience: (1) Physical Resilience which includes all the critical infrastructure and elements of the built environment (Biringer et al., 2013, M.Thayaparan et al., 2016, Koliou et al., 2018); (2) Human/Health Resilience which covers the skills, knowledge and the health outcomes of the population (Castleden et al., 2011, Lannigan et al., 2014, Links et al., 2017); (3) Economic Resilience which incorporates financial capital, livelihoods and economic facilities (Rose and Krausmann, 2013, Irwin et al., 2016); (4) Environmental Resilience which looks at natural resources, bio-diversity and the hazard itself (Ayyub, 2014, Smith, 2015, NAS, 2017); (5) Social Resilience which deals with social capital, networks and links between the population (Saja et al., 2018, Räsänen et al., 2020), and (6) Governance Resilience which is the ability of the local government and organizations to plan for, and deal with, the impacts of hazards (Council, 2015, Alexander, 2015). These dimensions were selected to represent the overall CDR as shown in Table 1. The choice of which dimension to focus on is based on the resilience problem being investigated by the assessment team.

Table 1 - Dimensions or Systems of the MOBILISE Community Disaster Resilience Framework (CDRF) 


\begin{tabular}{|l|l|}
\hline Dimension/System & Defined as (boundary conditions) \\
\hline $\begin{array}{l}\text { Physical } \\
\text { (Biringer et al., 2013, M.Thayaparan et al., 2016, } \\
\text { Koliou et al., 2018) }\end{array}$ & $\begin{array}{l}\text { Those facilities or structures that form a network of } \\
\text { structures that perform a vital function that is of } \\
\text { critical importance to the normal functioning of the } \\
\text { community (i.e. power/electrical network/grid, } \\
\text { telecoms, water mains/supply, road/transportation } \\
\text { networks etc.) }\end{array}$ \\
\hline $\begin{array}{l}\text { Human/Health } \\
\text { (Castleden et al., 2011, Lannigan et al., 2014, Links } \\
\text { et al., 2017) }\end{array}$ & $\begin{array}{l}\text { The human category focuses on the skills, } \\
\text { knowledge, labour and health outcomes of the } \\
\text { community }\end{array}$ \\
\hline $\begin{array}{l}\text { Economic } \\
\text { (Rose and Krausmann, 2013, Irwin et al., 2016) }\end{array}$ & $\begin{array}{l}\text { The economic resilience category includes both the } \\
\text { static assessment of a community's current } \\
\text { economy (economic activity) and the dynamic } \\
\text { assessment of a community's ability to } \\
\text { continuously sustain economic growth (economic } \\
\text { development). }\end{array}$ \\
\hline $\begin{array}{l}\text { Environmental } \\
\text { (Ayyub, 2014, Smith, 2015, NAS, 2017) }\end{array}$ & $\begin{array}{l}\text { Environmental or ecosystem resilience focuses on } \\
\text { the amount of disturbance an ecosystem can } \\
\text { absorb without drastically altering its functions, } \\
\text { processes and structures. }\end{array}$ \\
\hline $\begin{array}{l}\text { Social } \\
\text { (Saja et al., 2018, Räsänen et al., 2020) }\end{array}$ & $\begin{array}{l}\text { to connect with each other as individuals, groups } \\
\text { and organizations. }\end{array}$ \\
\hline $\begin{array}{l}\text { Governance } \\
\text { (Council, 2015, Alexander, 2015) }\end{array}$ & $\begin{array}{l}\text { Governance is an overreaching dimension that } \\
\text { looks at the application of laws, regulations and the } \\
\text { capacity of organizations to respond to, and assist, } \\
\text { in the case of disasters. }\end{array}$ \\
\hline
\end{tabular}

\section{Physical infrastructure Resilience}

Physical Infrastructure (PI) is recognized to be a critical element in developing and maintaining healthy economies and stable communities. It allows commerce, the movement of people, goods and information, and enables society's daily activities (Irwin et al., 2016). The ability of the PI system to function during adverse conditions and quickly recover to acceptable levels of service after an event is fundamental to the wellbeing of communities (Fekete, 2019). Accordingly, PI Resilience is intrinsically linked to the built environment and is defined in this research as those facilities, or structures, that form a network of structures that perform a vital function that is of critical importance to the normal functioning of the community. In the literature, scholars like Cimellaro et al. (2010), Peck and Simonovic (2013) and Koliou et al. (2018) have divided Physical Infrastructure into several sub-categories to indicate the elements of the built environment that need to be considered. The PI system which focuses on a community's built environment and its sub-categories are shown in Table 2.

Table 2 - Sub-components/Elements of the Built Environment

\section{No. Element of the Built Environment Description}

1 Buildings 


\begin{tabular}{|l|l|l|}
\hline No. & Element of the Built Environment & Description \\
\hline $\mathbf{2}$ & Lifeline Systems & $\begin{array}{l}\text { Those facilities/structures that form a network of } \\
\text { structures that perform a vital function that is of } \\
\text { critical importance to the normal functioning of the } \\
\text { community (i.e. power/electrical network/grid, } \\
\text { telecoms, water mains/supply, road/transportation } \\
\text { networks, etc.). }\end{array}$ \\
\hline $\mathbf{3}$ & Critical Facilities & $\begin{array}{l}\text { Those facilities/structures that have a specific } \\
\text { function and are measured according to the } \\
\text { capacities outlined above (i.e. hospitals, schools, local } \\
\text { government buildings, police stations, etc.). }\end{array}$ \\
\hline $\mathbf{4}$ & Early warning systems & $\begin{array}{l}\text { The facilities/structures that help the community } \\
\text { monitor aspects of the hazard environment and can } \\
\text { help warn citizens and organizations prior to adverse } \\
\text { impacts occurring. }\end{array}$ \\
\hline $\mathbf{5}$ & Green infrastructure & $\begin{array}{l}\text { Aspects of the built environment converted to green } \\
\text { infrastructure that helps the community deal with } \\
\text { hazards. }\end{array}$ \\
\hline
\end{tabular}

In order to measure resilience, the research team identified three capacities of disaster resilience anticipative, absorptive and restorative - as being representative of the range of broad considerations for assessing resilience for operationalization. To assess the resilience of Physical Infrastructure, in terms of the study's approach, a Physical Infrastructure Capacity Assessment Tool (PI-CAT) was developed using participatory methods - see the next section. The PI-CAT can be operationalized through participatory methods to provide a stakeholder-defined resilience assessment tool from a library of Physical Infrastructure resilience indicators. This will ensure a more "fit-for-purpose" assessment tool based on the perspectives, experience and needs of the community's key stakeholders. The PI-CAT allows for greater customization of, and adaptability to, the disaster resilience context of a specific community.

\section{Methodology}

This paper uses a Q-methods' approach to operationalizing the measurement of Physical Infrastructure resilience. The approach uses a mixed methods' approach, utilising both the qualitative method (such as interviews and focus group discussions) and the quantitative method (such as the ranking tool developed and used for selecting measures in this study, called the Q-sort, and a factor analysis component that will be applied in future work). The steps required in $Q$ methods are shown in Figure 1 and, at each step, different tools are utilized to better understand the phenomenon under study (Watts and Stenner, 2012, Alderson et al., 2018). In this case, these measures or indicators are used to develop a consensus on an index to measure the resilience of a community. The research team used Q-sorting, one of the steps in Q-methods, to allow participants to rank and select the measures that are to be included in the PI-CAT. 
Complex concepts like community disaster resilience require an understanding of diverse groups of peoples' views, opinions or beliefs about resilience issues. Q-methods is a relatively new method in disaster management research to examine resilience questions from a more subjective approach to resilience measurement where stakeholders such as decision makers, local government authorities and community members' perspectives, experience and knowledge can be used as inputs into the process (Béné et al., 2016, Jones and Tanner, 2017). Objective approaches to resilience measurement depend on more standardised measures that are mostly, though not exclusively, based on secondary data collected about the community from other sources (Clare et al., 2017). Qmethods combines qualitative and quantitative techniques which allow researchers to firstly identify the range of the views that exist on a topic and then describe in-depth those viewpoints (Watts and Stenner, 2012, Zabala, 2014).

The Q-method is being used here in this study to help define PI resilience (and its sub-components) and to determine the inclusion (and exclusion) of measures into an index of community level capacities for physical resilience in the built environment. By using Q-methods to design and refine the PI-CAT, the resilience assessment process gets a participatory approach built into its implementation whereby key stakeholders are an inherent part of the resilience assessment process (Clare et al., 2017). Although the method works well with small, selected samples of individuals, it is not intended to be generalised to a larger population, hence, its appropriateness for ranking among the expert groups used in this study (Raadgever et al., 2008, Zabala and Pascual, 2016). Applying Qmethods within this study consisted of 5 steps as detailed in Figure 1.

\section{STEPS:}

1. Collection of
all possible
statements
about the issue
at hand (the
"Concourse")
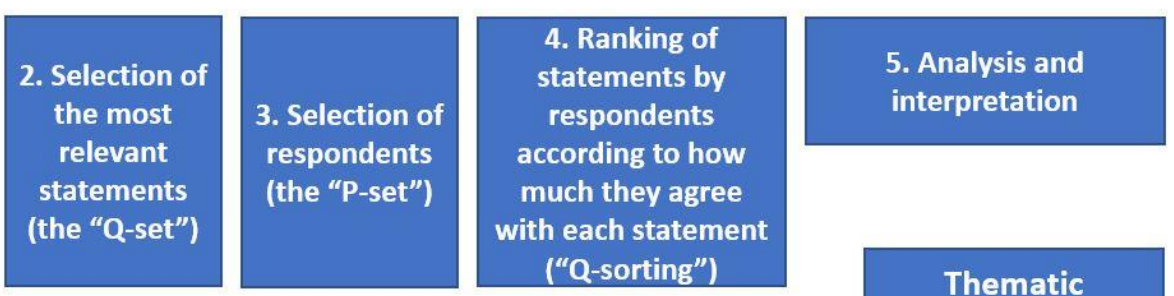

METHODS:
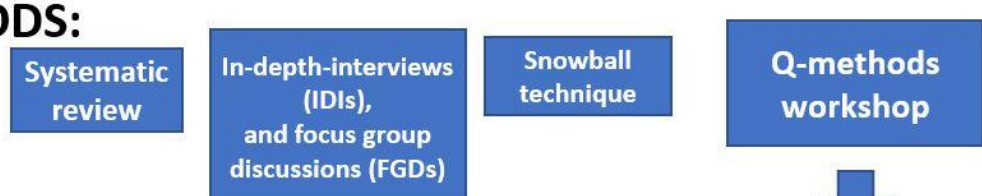

DATA COLLECTION:
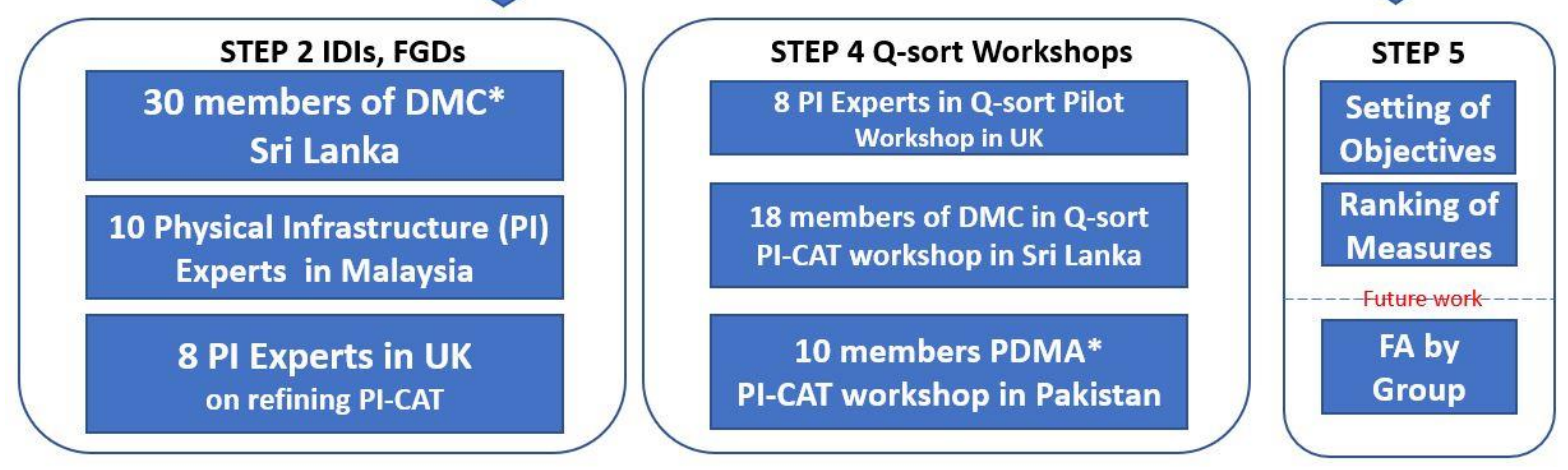

${ }^{*}$ DMC $=$ Disaster Management Centre in Sri Lanka; PDMA = Provincial Disaster Management Authority, Khyber Pakhtunkhwa, Pakistan; and PI-CAT = Physical Infrastructure Capacity Assessment Tool.

Figure 1 - Steps of the study, methods used and sample size 


\section{Developing the "Concourse", the "Q-set" and the "P-set" for the study}

This paper focuses on the built environment, stated here as the PI resilience of a community. Every study using Q-methods begins with a collection of items, pictures or statements called the "Concourse" developed through a preliminary qualitative study (Watts and Stenner, 2012). As part of this first step (as shown in Figure 1), a systematic review of 31 resilience frameworks was conducted and thematically analyzed (Tariq et al., 2020). The results of this review were used as the "Concourse" in this study and this resulted in the creation of an initial library of 317 measures (Cimellaro et al., 2010, Joerin et al., 2012, Ayyub, 2014, Ostadtaghizadeh et al., 2015, Irwin et al., 2016, Sharifi, 2016, Cutter, 2018, Jones, 2019). These measures were then looked at in detail by the research team and were highlighted for further refinement and validation by interviews and focus group discussions (as shown in Figure 1) with subject matter expert groups through several steps of the research study to form 30 to 40 statements for each capacity. These refined sets were the set of statements used as " $Q$ set" (step 2 in Figure 1 ) for each capacity in subsequent stages.

Figure 1 also looks at the number and types of participants in the study in Steps 2 and 4 of the research where, at Step 2, interviews and focus group discussions were conducted with key stakeholders to get feedback on the definitions of the core concepts such as Physical Infrastructure resilience, its sub-components, the three resilience capacities and also the initial set of measures for the library. In step 4 of the research, Q-sort workshops were conducted where further validation of the definitions, sub-components and measures in the library was undertaken. The participants in a $Q$ study are called the "P-set" and for the workshops they were drawn from key project stakeholders across the three project countries of Malaysia, Pakistan and Sri Lanka. The snowball sampling technique was used where participants in the first set of interviews and focus groups were asked to identify colleagues and experts in PI resilience, who were subsequently contacted for participation in the workshops. The Q-sorts were completed with these participants to determine the important measures from the stakeholders' point of views. The total number of participants and the groups they belonged to are shown in Figure 1.

As preparation for both Steps 2 and 4, the keywords from the definitions in the review, the subcategories list and the indicators identified in the literature review were then converted to "statements" on cards and were entered in an online tool called $Q$ sortware which allowed the Qsort to be administered to individuals and through focus groups. The statements are the output from the Concourse in Step 1 and were worded the same as the actual measures found in the literature. These statements were then sorted and ranked for each of three capacities, which created a stakeholder designed PI resilience measurement tool for the community resilience context being explored. Step 2 required conducting several interviews, and focus groups, with relevant stakeholders to go through the statements, to rank them according to importance for inclusion in the assessment tool and to finalize a Q-set of 30 to 40 measures for each capacity (anticipatory, absorptive and restorative). The interviews and focus group discussions (FGDs) conducted in Step 2 were implemented face-to-face by the research team and took about forty-five minutes and one and a half hours each respectively. In the FGDs, materials were first presented, and then participants were asked to work in groups.

Similarly, at Step 4 the Q-sort workshops were conducted face-to-face with participants divided into three capacity groups by self-selection where they each completed the Q-sort exercise as designed. The sorting process allowed stakeholders to include essential measures in the PI-CAT and to drop others, ranking them in order of preference from the most important $(+5)$ to the least important $(-5)$. 
Q-sort uses a forced choice, quasi-normal sorting distribution designed for use with a 48 item Q-set. This contains 11 ranking variables ranging from +5 to -5 which sets the number of items at each value (two at +5 , three at +4 , and so on).

The more times Q-sort exercises are undertaken with stakeholders the larger the library of available PI-CAT preferences can become, hence offering additional insights into how different stakeholders think about community disaster resilience, the capacities, and their link to the resilience problem being considered. As more stakeholders become involved in the study in the future, factor analysis by groups will be conducted exploring the relationship between PI-CAT preferences and type of participants and groups.

\section{Findings}

\section{Capacities of Resilient Communities}

At Step 1 of the research, the literature review indicated a large number of objectives for each of the capacities and these were used in several consultations and focus group discussions as part of cocreation workshops with Physical Infrastructure and built environment experts conducted across the four countries (UK, Malaysia, Pakistan and Sri Lanka). The research team focused on validating the objectives of the three capacities for measuring Physical Infrastructure resilience and reducing the large number of objectives to a more manageable number according to stakeholders' feedback. Through interviews with experts, the team checked for validity of the objectives as extracted in the literature review and received feedback that they were too broad in coverage and required a more detailed approach. Participants recommended dropping several objectives and combining others into one allowing for a more focused assessment. For example, for Absorptive capacity several measures related to the robustness, quality or strength of the infrastructure were combined into an indicator called Resistance. Similarly, in Restorative Capacity, several indicators related to costs were combined to form an indicator for Economics of Restoration. A focus group discussion was conducted after the interviews were completed to consolidate these indicators. The participants were also asked to recommend other colleagues and experts who could become potential participants in subsequent focus group discussions and workshops. The final output from the focus group discussion regarding the objectives for measuring the PI resilience of the built environment are shown in Table $\mathbf{3}$ - for comparison the initial and final set chosen by participants are both shown. The final set of objectives reflect the opinions and preferences of the subject matter experts on how the capacity framework can be practically used to measure Physical Resilience.

Table 3. Initial objectives from the literature and the final list of objectives after interviews and focus group discussions in Step 2.

\begin{tabular}{|c|c|c|}
\hline Capacities & $\begin{array}{l}\text { Objectives from the Literature } \\
\text { (Initial Q-set for each capacity) }\end{array}$ & $\begin{array}{l}\text { Final Objectives } \\
\text { (after workshops) }\end{array}$ \\
\hline $\begin{array}{l}\text { Anticipatory } \\
\text { Capacity } \\
\text { (Prior (2014); } \\
\text { UNDP (2014); } \\
\text { Council (2015); } \\
\text { Koliou et al. } \\
\text { (2018)) }\end{array}$ & $\begin{array}{l}\text { 1. Awareness of potential hazards } \\
\text { 2. Quality of infrastructure } \\
\text { 3. Pre-event functionality of the } \\
\text { infrastructure } \\
\text { 4. Quality/extent of mitigating features } \\
\text { 5. Quality of disturbance } \\
\text { planning/response } \\
\text { 6. Quality of crisis } \\
\text { communication/information sharing } \\
\text { 7. Learnability }\end{array}$ & $\begin{array}{l}\text { 1. Awareness of } \\
\text { potential hazards } \\
\text { 2. Quality/Extent of } \\
\text { mitigating features } \\
\text { 3. Learn-ability/Training } \\
\text { 4. Communication } \\
\text { Systems/Information } \\
\text { sharing } \\
\text { 5. Quality of } \\
\text { disturbance } \\
\text { planning/Response }\end{array}$ \\
\hline
\end{tabular}




\begin{tabular}{|c|c|c|}
\hline $\begin{array}{l}\text { Absorptive } \\
\text { Capacity } \\
\text { (Cimellaro et } \\
\text { al. (2010); } \\
\text { Cabinet Office } \\
\text { (2011); Watson } \\
\text { et al. (2014); } \\
\text { Koliou et al. } \\
\text { (2018)) }\end{array}$ & $\begin{array}{l}\text { 1. Systems' failure (unavailability of assets) } \\
\text { 2. Severity of failure } \\
\text { 3. Just in time delivery - Reliability } \\
\text { 4. Post-event functionality } \\
\text { 5. Resistance } \\
\text { 6. Robustness } \\
\text { 7. Withstanding } \\
\text { 8. Redundancy } \\
\text { 9. Resourcefulness } \\
\text { 10. Response } \\
\text { 11. Economic sustainability } \\
\text { 12. Interoperability }\end{array}$ & $\begin{array}{l}\text { 1. System failure } \\
\text { 2. Severity of failure } \\
\text { 3. Resistance }\end{array}$ \\
\hline $\begin{array}{l}\text { Restorative } \\
\text { Capacity } \\
\text { (Constas et al. } \\
\text { (2014); } \\
\text { Council (2015); } \\
\text { Koliou et al. } \\
(2018) \text { ) }\end{array}$ & $\begin{array}{l}\text { 1. Post-event damage assessment } \\
\text { 2. Recovery time post-event } \\
\text { 3. Recovery/loss ratio } \\
\text { 4. Cost of reinstating functionality post- } \\
\text { event } \\
\text { 5. Substitutability (replacement of service) } \\
\text { 6. Adaptability/flexibility } \\
\text { 7. Impact reducing availability } \\
\text { 8. Consequences reducing availability }\end{array}$ & $\begin{array}{l}\text { 1. Post-event damage } \\
\text { assessment } \\
\text { 2. Recovery time } \\
\text { 3. Economics of } \\
\text { restoration }\end{array}$ \\
\hline
\end{tabular}

Accordingly, the initial set of 317 measures was then reduced to 128 measures to form the final " $Q$ set" for this study via an initial focus group discussion and sharing with an expert panel group as indicated in Figure 1 Step 2. In order to cover the many perspectives, these statements were then shared with colleagues and extended research team members to get their feedback on reliability and comprehensiveness. After the feedback from this expert group, an internal workshop among the research team was conducted resulting in the selection of the most relevant measures/indicators to be included in the "Q-set", in order to make the Q-workshop size and time duration manageable. The selection of final set of measures for each capacity was based on how they best matched the objectives identified in the previous step and on the clarity of the wording of the measures to ensure maximum engagement of the participants in the workshops.

\section{Q-workshops}

In the Q-sort workshops of Step 4, the participants were asked to divide into three groups (one for each capacity) and were asked to rank the Q-sets to the best of their ability and opinion by achieving consensus among all those in the group. This set of workshops resulted in the finalization of the PICAT which consists of the thirty-eight final indicators and their ranking in order of preference by each capacity. The results from these workshops is summarised by capacity in Table $\mathbf{4}$ where an average of the ranks of each statement from the workshops is also shown.

Table 4 - Capacities and ranking of measures/indicators for PI resilience assessment.

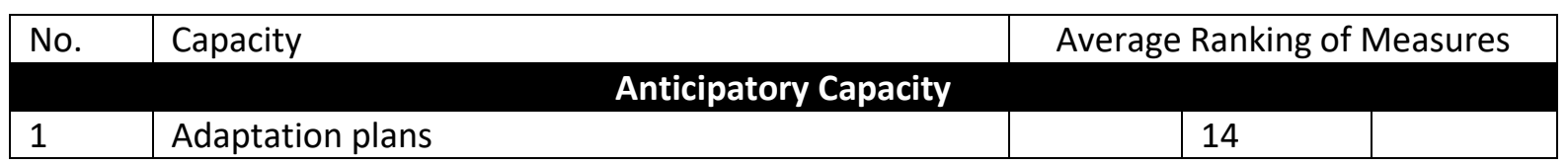




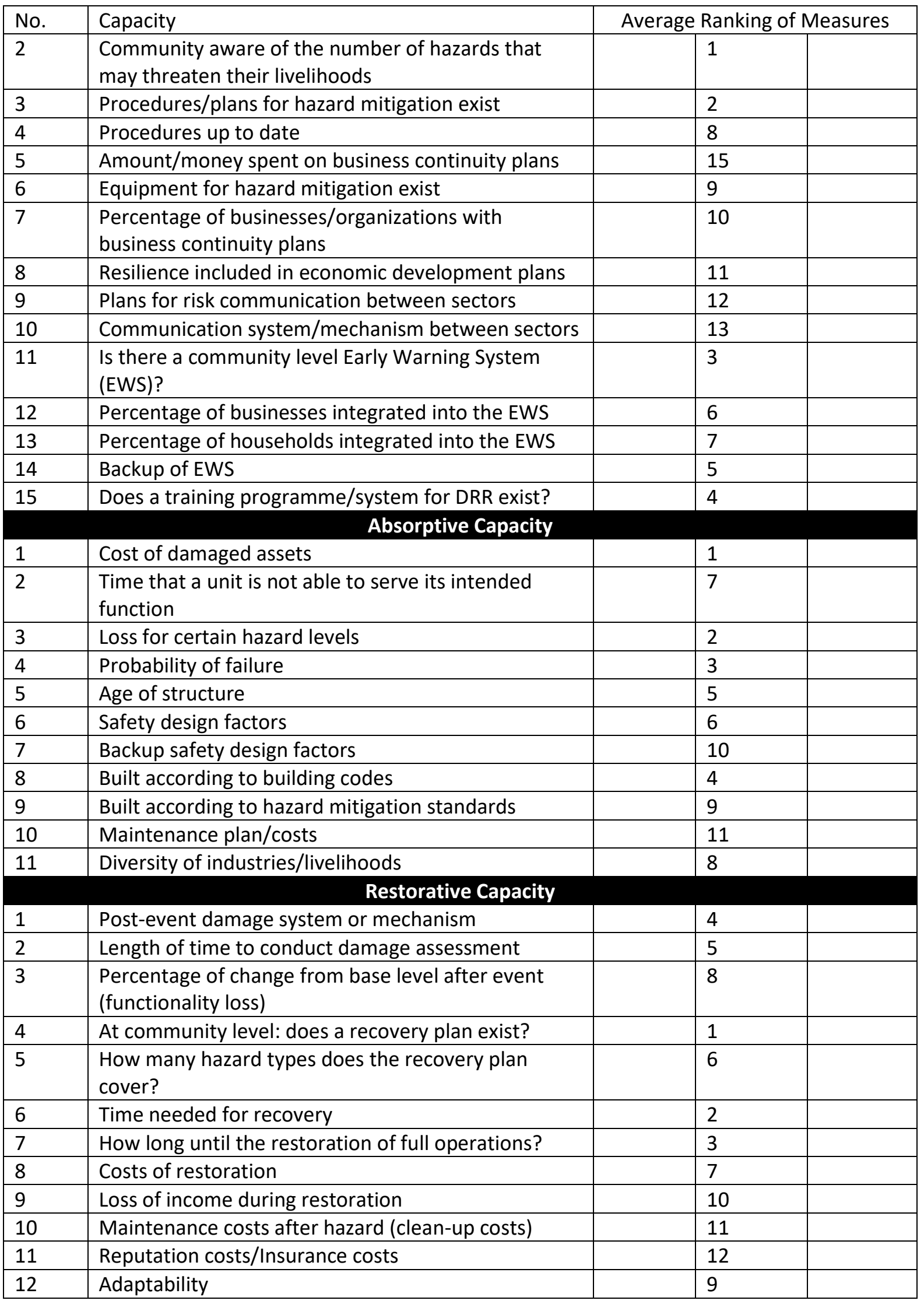

For the anticipatory capacity, participants considered that hazard awareness was a key measure or indicator that described the community's preparedness best. This was followed by an emphasis on 
preparedness plans and the presence or absence of early warning systems. Not surprisingly, including resilience in development plans did not rank very high among the participants. Cavaye and Ross (2019) indicate that this disconnect is perhaps related to either silo thinking among practitioners or because of underlying power relationships that exist between different types of decision makers - those in disaster response concerned with dealing with a disaster and those in urban planning dealing with growth (Brown, 2016, Cavaye and Ross, 2019). Alternatively, the lack of linkage between resilience and development plans may be because participants thought that the measure belonged in the restorative capacity rather than in the anticipatory capacity. Similarly, adaptation plans, money for business continuity plans, and prevalence of business continuity plans in the community were ranked lower than expected suggesting that there is still a lack of awareness among practitioners on the benefits of private sector business continuity planning (Kliem and Richie, 2015). This could also be, at least in these participant groups, due to the low expectations regarding resources being available for preparedness, mitigation and DRR in low- and middle-income countries (Jones et al., 2014) indicating that the answer to this question may be different in other settings.

In the ranking exercise for the absorptive capacity, participants selected the cost of damaged assets, damage curves for different levels of the hazard, and the construction of PI according to building codes as of the highest priority to measure. The participants in the Disaster Management Centre (DMC) and Provincial Disaster Management Authority (PDMA) workshops, in Colombo and Peshawar respectively, reportedly selected these measures as important due to their primary occupational responsibilities. i.e. to assess damages at the community level. Rapid damage assessments are a key function of disaster management authority staff and are of critical importance for decision making for response, relief and recovery activities (Lallemant et al., 2017). After the measure for building codes and standards, the age of the structure and safety design factors of the build/or asset were considered as next of importance to understand the vulnerability of the community's physical assets. Overall, measures on built according to mitigation standards, back-up safety features in the infrastructure, and maintenance plans/costs were ranked lowest with participants. The measures on built to mitigation standards was ranked low because it had similar wording to the first-choice measure, built according to building code/standards, and participants found it difficult to differentiate between them. For the other two measures, the most common reason given was that the other measures were simply more important, and it was hard to decide. This difficulty in selection may mean these measures were not explained properly, in comparison to others and required clearer language or wording.

In the restorative capacity, the importance of a recovery plan, the calculation of time to service restoration, and the presence of a post-event damage assessment mechanism were highlighted as the most important for recovery. Participants reported that recovery plans at the local level give decision makers more information on local capacities and can help restore basic services and functions quicker. Platt (2017) has also emphasised the role of properly developed recovery plans in affecting both the speed and quality of recovery, while Clare et al. (2017) have shown that planning can help the quality of recovery if developed properly in consultation with local community groups. Additionally, the time taken to recover from a disaster event (with respect to the last event) and the time taken to restore basic services (with respect to the last event) where both selected as key measures by the participants to represent the restorative capacity of a community. Finally, measures on loss of income (of service providers), maintenance and clean-up costs were ranked low in importance. The least important measure considered for restorative capacity was reputation and insurance costs to the service providers or utility companies. All three of these measures were from the Economics of Restoration indicator, perhaps revealing a selection bias against those measures that require allocation of additional resources or finances, as indicated previously practitioners may 
have lower expectations for securing funding for disaster management policies in low resource settings (Jones et al., 2014).

\section{Discussion}

A lack of consensus in the literature as to how community resilience can be operationalized in a measurable framework creates issues regarding the practical implementation of community resilience assessment tools within at-risk communities (Norris et al., 2008, Cimellaro et al., 2010). Some academics such as Levine (2014) argue that the quantification of a concept like resilience misses the point and reduces its value by taking away the focus from creating the right type of discussions on DRR among stakeholders. A tool that cannot be defined (and hence implemented) properly may make some practitioners and policymakers uncomfortable in using the concept practically in their everyday work processes (Ramalingam, 2013, Clare et al., 2017). Clare et al. (2017) suggest that resilience assessment tools developed without considering the perspectives, experience and knowledge of its stakeholders run the risk of becoming invalid for the purpose for which they are being designed. Such not "fit-for-purpose" resilience assessment processes or frameworks can also present a problem for systematic research and for the development of evidence-based policy and may lead to less than equitable outcomes for DRR interventions (Matin et al., 2018). The lack of consensus does not help to solve the practitioner's dilemma regarding measurement which makes it hard to implement and, hence, hard to include as part of a systematic risk assessment process for Disaster Management Authorities (DMAs).

This study thus identifies a need to focus on developing a common conceptual and measurement model and, in so doing, also provides a tool that can help researchers reach that consensus to measure physical resilience. The CDR framework for PI resilience in the built environment provides both a robust approach to assessing a community's physical resilience (based on key characteristics and indicators) and a customizable one according to the needs of the stakeholders. The structure of the PI Resilience framework remains the same as top-down approaches but at the indicator/measures' level it can be contextualized by engaging the key stakeholders at the community and local government level within the same broad structure of assessment. This framework can also be operationalized among different communities and in different disaster contexts and can be further refined according to stakeholder preferences and requirements. Further application in case studies is required so that multi-conditional testing of the indicators in different contexts can help improve the functionality of the framework and the evidence-based process of modification and verification of the proposed indicators.

It is important to note that the study uses a combined subjective and objective approach depending on the stages of the study. Steps 2 and 4 used a subjective approach to define PI resilience, its subcategories and how capacities can be measured, i.e. developing a case context PI-CAT. The measures and indicators chosen for PI-CAT are, in the most part, themselves objective in nature, i.e. using either primary or secondary data, as in household education levels or health outcomes, and are applied as before, i.e. designed as objective measures. Hence, the resilience assessment tool uses the same types of data that the practitioners are already familiar with and does not require them to develop new skill sets.

\section{Limitations}

The application of the library of measures' approach in the context of the CDR Physical Infrastructure framework in this study needs to be evaluated further in additional workshops and in use case studies. The researchers wish to point out that not all of the measures included in the library are easy to measure, for example those measures that require a valuation of social or human factors 
such as learning or training capacities that play a role in the running and maintenance of PI where proxy indicators can be used.

Additionally, a key limitation of such subjective approaches (as used in the study) are that more care and attention are needed to avoid cognitive biases, social desirability and priming (Jones, 2019). The process of stakeholder consultation itself is time consuming and may be dominated by the representation of fewer stakeholders than is ideal for the assessment which can adversely impact upon who is represented and how PI resilience is categorized.

\section{Policy and Practical Implications}

The participatory workshop approach to building resilience assessment tools allows stakeholders at various levels to select (or to at least agree on and validate) suitable measures of Physical Infrastructure resilience that, in their perspective, best represents the resilience issues in their community. The inclusion of a subjective characterisation process for resilience assessment is a novel way of developing a more "fit-for-purpose" set of tools and can be useful where practitioners and policy makers want to contextualize the tool to suit their requirements. This subjective process also meets the requirements of international development agencies and partners that emphasize the need for greater inclusiveness in the disaster risk reduction planning of marginalized communities.

\section{Conclusion}

This research proposes a novel method of indicator selection for the measurement of community disaster resilience as part of the community resilience assessment process and can be conducted with several stakeholder groups ranging from local and state government representatives, political decision makers to the community members themselves. The tools and methods developed in this paper allow for the application of a mixed methods' approach to calibrate and contextualise the resilience measurement tool according to the community stakeholder groups themselves and allows for the sharing of perspectives, goals and motivations with regard to community disaster resilience and how to improve it over time. Similarly, researchers in the built environment can utilize the same framework for advancing knowledge concerning Physical Infrastructure resilience measurement by adapting it to the context of their research.

\section{Future Works}

Additional Q-sort workshops are needed to validate the framework and will be carried out in the remainder of the MOBILISE project's duration including a factor analysis of preferences by stakeholder groups in each of the three countries. Also, additional work on the other 5 dimensions (Human/Health, Environmental, Economic, Social and Governance) is also required to test the applicability of the method among other expert and stakeholder groups.

Acknowledgement: The author expresses his gratitude to the Global Challenges Research Fund (GCRF) and the Engineering and Physical Sciences Research Council (EPSRC) for the financial support under the International Grant, EP/PO28543/1, entitled "A Collaborative Multi-Agency Platform for Building Resilient Communities". 
ALDERSON, S., FOY, R., BRYANT, L., AHMED, S. \& HOUSE, A. 2018. Using Q-methodology to guide the implementation of new healthcare policies. BMJ Quality \&amp; Safety, 27, 737-742.

ALEXANDER, D. 2015. Evaluation of civil protection programmes, with a case study from Mexico. Disaster Prevention and Management, 24, 263-283.

ANDERSEN, D. F., VENNIX, J. A., RICHARDSON, G. P. \& ROUWETTE, E. A. 2007. Group model building: problem structing, policy simulation and decision support. Journal of the Operational Research Society, 691-694.

AYYUB, B. M. 2014. Systems Resilience for Multihazard Environments: Definition, Metrics, and Valuation for Decision Making. Risk Analysis, 34, 340-355.

BAHADUR, PETERS, K., WILKINSON, E., PICHON, F., GRAY, K. \& TANNER, T. 2015. The 3As: Tracking Resilience Across Braced,. In: PAPER, W. (ed.) BRACED Knowledge Manager. [Online] Available from: http://www.braced.org/ Accessed April 2015.

BECCARI, B. 2016. A Comparative Analysis of Disaster Risk, Vulnerability and Resilience Composite Indicators. PLOS Currents Disasters, 1.

BÉNÉ, GODFREY, NEWSHAM, A. \& DAVIES, M. 2012. Resilience: new utopia or new tyranny? Potentials and limits of the concept of resilience in relation to vulnerability reduction programmes. Brighton: : Institute of Development Studies. .

BÉNÉ, C., AL-HASSAN, R. M., AMARASINGHE, O., FONG, P., OCRAN, J., ONUMAH, E., RATUNIATA, R., TUYEN, T. V., MCGREGOR, J. A. \& MILLS, D. J. 2016. Is resilience socially constructed? Empirical evidence from Fiji, Ghana, Sri Lanka, and Vietnam. Global Environmental Change, 38, 153-170.

BIRINGER, VUGRIN, E. \& WARREN, D. 2013. Critical infrastructure system security and resiliency, CRC press.

BROWN, K. 2016. Resilience, Development and Global Change, London, Routledge.

CASTLEDEN, M., MCKEE, M., MURRAY, V. \& LEONARDI, G. 2011. Resilience thinking in health protection. Journal of Public Health, 33, 369-377.

CAVAYE, J. \& ROSS, H. 2019. Community resilience and community development: What mutual opportunities arise from interactions between the two concepts? Community Development, 50, 181-200.

CIMELLARO, G. P., REINHORN, A. M. \& BRUNEAU, M. 2010. Framework for analytical quantification of disaster resilience. Engineering Structures, 32, 3639-3649.

CLARE, A., GRABER, R., JONES, L. \& CONWAY, D. 2017. Subjective measures of climate resilience: What is the added value for policy and programming? Global Environmental Change, 46, 1722.

CONSTAS, FRANKENBERGER, HODDINOTT, MOCK, ROMANO, BENE \& MAXWELL, A. 2014. A common analytical model for resilience measurement: Causal framework and methodological options. FSIN Technical Series. FAO.

COUNCIL, N. R. 2015. Developing a Framework for Measuring Community Resilience: Summary of a Workshop, Washington, DC, The National Academies Press.

CUTTER, S. 2018. Linkages between vulnerability and resilience. In: FUCHS, S. \& THALER, T. (eds.) Vulnerability and Resilience to Natural Hazards. Cambridge: Cambridge University Press.

CUTTER, S. L. 2016. Resilience to What? Resilience for Whom? The Geographical Journal, 182, 110113.

FEKETE, A. 2019. Critical infrastructure and flood resilience: Cascading effects beyond water. WIREs Water, 6, e1370.

FOLKE, CARPENTER, S. R., WALKER, B., SCHEFFER, M., CHAPIN, T. \& ROCKSTRÖM, J. 2010. Resilience thinking: integrating resilience, adaptability and transformability. Ecology and Society, 15.

HOVMAND, P. 2014. Community Based System Dynamics, Springer Link. 
IRWIN, S., SCHARDONG, A., SIMONOVIC, S. \& NIRUPAMA, N. 2016. ResilSIM-A Decision Support Tool for Estimating Resilience of Urban Systems. Water, 8, 377.

JOERIN, J., SHAW, R., TAKEUCHI, Y. \& KRISHNAMURTHY, R. 2012. Assessing community resilience to climate-related disasters in Chennai, India. International Journal of Disaster Risk Reduction, 1, 44-54.

JONES, L. 2019. Resilience isn't the same for all: Comparing subjective and objective approaches to resilience measurement. WIREs Climate Change, 10, e552.

JONES, L. \& TANNER, T. 2017. 'Subjective resilience': using perceptions to quantify household resilience to climate extremes and disasters. Regional Environmental Change, 17, 229-243.

JONES, S., OVEN, K. J., MANYENA, B. \& ARYAL, K. 2014. Governance struggles and policy processes in disaster risk reduction: A case study from Nepal. Geoforum, 57, 78-90.

KELLETT \& PETERS 2014. Dare to Prepare: Taking Risk Seriously. Working Papers. London: ODI.

KLIEM, R. L. \& RICHIE, G. D. 2015. Business Continuity Planning: A Project Management Approach, CRC Press.

KOLIOU, M., VAN DE LINDT, J. W., MCALLISTER, T. P., ELLINGWOOD, B. R., DILLARD, M. \& CUTLER, H. 2018. State of the research in community resilience: progress and challenges. Sustainable and resilient infrastructure, No Volume, 10.1080/23789689.2017.1418547.

LALLEMANT, D., SODEN, R., RUBINYI, S., LOOS, S., BARNS, K. \& BHATTACHARJEE, G. 2017. PostDisaster Damage Assessments as Catalysts for Recovery: A Look at Assessments Conducted in the Wake of the 2015 Gorkha, Nepal, Earthquake. Earthquake Spectra, 33, 435-451.

LANNIGAN, R., OWRANGI, A. \& SIMONOVIC, S. 2014. An approach to developing a composite measure for human health as an input to a dynamic systems model for investigating city resilience. 6th International Conference on Flood Management. Sao Paulo, Brazil.

LEVINE, S. 2014. Assessing resilience: why quantification misses the point. Humanitarian Policy Group Working Title. Overseas Development Institute.

LINKS, J. M., SCHWARTZ, B. S., LIN, S., KANAREK, N., MITRANI-REISER, J., SELL, T. K., WATSON, C. R., WARD, D., SLEMP, C., BURHANS, R., GILL, K., IGUSA, T., ZHAO, X., AGUIRRE, B., TRAINOR, J., NIGG, J., INGLESBY, T., CARBONE, E. \& KENDRA, J. M. 2017. COPEWELL: A Conceptual Framework and System Dynamics Model for Predicting Community Functioning and Resilience After Disasters. Disaster Medicine and Public Health Preparedness, 12, 127-137.

M.THAYAPARAN, C.P.PATHIRAGE, U.KULATUNGA \& T.FERNANDO 2016. A Resilience Framework for Critical Infrastructure 12th International Conference of the International Institute for Infrastructure Resilience and Reconstruction (I3R2). Kandy, Sri Lanka.

MATIN, N., FORRESTER, J. \& ENSOR, J. 2018. What is equitable resilience? World Development, 109, 197-205.

NAS 2017. Measures of Community Resilience for Local Decision Makers: Proceedings of a Workshop, Washington, DC, The National Academies Press.

NORRIS, F. H., STEVENS, S. P., PFEFFERBAUM, B., WYCHE, K. F. \& PFEFFERBAUM, R. L. 2008. Community Resilience as a Metaphor, Theory, Set of Capacities, and Strategy for Disaster Readiness. American Journal of Community Psychology, 41, 127-150.

OSTADTAGHIZADEH, A., ARDALAN, A., PATON, D., JABBARI, H. \& KHANKEH, H. R. 2015. Community disaster resilience: a systematic review on assessment models and tools. PLoS currents, 7, ecurrents.dis.f224ef8efbdfcf1d508dd0de4d8210ed.

PATEL, S. S., ROGERS, M. B., AMLÔT, R. \& RUBIN, G. J. 2017. What Do We Mean by 'Community Resilience'? A Systematic Literature Review of How It Is Defined in the Literature. PLoS currents, 9, ecurrents.dis.db775aff25efc5ac4f0660ad9c9f7db2.

PECK, A. \& SIMONOVIC, S. P. 2013. Coastal Cities at Risk (CCaR): Generic System Dynamics Simulation Models for Use with City Resilience Simulator. Water Resources Research. London, Ontario, Canada: Facility for Intelligent Decision Support. 
PLATT, S. Factors affecting the speed and quality of post-disaster recovery and resilience. International Conference on Earthquake Engineering and Structural Dynamics, 2017. Springer, 369-403.

RAADGEVER, G. T., MOSTERT, E. \& VAN DE GIESEN, N. C. 2008. Identification of stakeholder perspectives on future flood management in the Rhine basin using Q methodology. Hydrol. Earth Syst. Sci., 12, 1097-1109.

RAMALINGAM, B. 2013. Aid on the edge of chaos: rethinking international cooperation in a complex world, Oxford University Press.

RÄSÄNEN, A., LEIN, H., BIRD, D. \& SETTEN, G. 2020. Conceptualizing community in disaster risk management. International Journal of Disaster Risk Reduction, 45, 101485.

REYERS, B., NEL, J. L., O'FARRELL, P. J., SITAS, N. \& NEL, D. C. 2015. Navigating complexity through knowledge coproduction: Mainstreaming ecosystem services into disaster risk reduction. Proceedings of the National Academy of Sciences, 112, 7362-7368.

ROGERS, P. 2011. Development of Resilient Australia: Enhancing the PPRR approach with anticipation, assessment and registration of risks. Australian Journal of Emergency Management, 26, 54-58.

ROSE, A. \& KRAUSMANN, E. 2013. An economic framework for the development of a resilience index for business recovery. International Journal of Disaster Risk Reduction, 5, 73-83.

SAJA, A. M. A., TEO, M., GOONETILLEKE, A. \& ZIYATH, A. M. 2018. An inclusive and adaptive framework for measuring social resilience to disasters. International Journal of Disaster Risk Reduction, 28, 862-873.

SERFILIPPI, E. \& RAMNATH, G. 2018. Resilience measurement and conceptual frameworks: A review of the literature. Annals of Public and Cooperative Economics, 89, 645-664.

SHARIFI, A. 2016. A critical review of selected tools for assessing community resilience. Ecological Indicators, 69, 629-647.

SMITH, K. 2015. Environmental hazards assessing risk and reducing disaster. Johanneshov: MTM.

TARIQ, H., PATHIRAGE, C. P. \& FERNANDO, T. 2020. Measuring Community Disaster Resilience at local levels: An adaptable framework. THINKLab Working Papers. University of Salford.

THAYAPARAN, M., INGIRIGE, B., PATHIRAGE, C. P., KULATUNGA, U. \& FERNANDO, T. 2016. A Resilience Framework for Critical Infrastructure. 12th International conference of the International Institute for Infrastructure Resilience and Reconstruction. Kandy Sri Lanka.

UN/ESCAP 2015. Disasters in Asia and the Pacific: 2015 Year in Review. In: PACIFIC, E. A. S. C. F. A. A. T. (ed.). United Nations

UNDP 2014. Community Based Resilience Analysis (CoBRA): Conceptual Framework and Methodology. United Nations.

UNISDR. 2009. Terminology [Online] [Online]. UNISDR. Available: http://www.unisdr.org/we/inform/terminology [Accessed 8 August 2017].

UNISDR 2013. Global Assessment Report 2013. Global Assessment Report on Disaster Risk Reduction: From Shared Risk to Shared Value: The business case for Disaster Risk Reduction. Geneva, Switzerland: UNISDR.

UNISDR 2019. Global Assessment Report 2019. Global Assessment Report on Disaster Risk Reduction. Geneva, Switzerland: UNISDR.

WATTS, S. \& STENNER, P. 2012. Doing Q Methodological Research: Theory, Method \& Interpretation, SAGE Publications.

WISNER, B., BLAIKIE, P., CANNON, T. \& \& DAVIS, I. 2004. At Risk: Natural Hazards, People's Vulnerability and Disasters., Routledge.

ZABALA, A. 2014. qmethod: A Package to Explore Human Perspectives Using Q Methodology. $R$ Journal, 6, 163-173.

ZABALA, A. \& PASCUAL, U. 2016. Bootstrapping Q Methodology to Improve the Understanding of Human Perspectives. PLOS ONE, 11, e0148087. 